Article

\title{
A High-Precision LiDAR-Based Method for Surveying and Classifying Coastal Notches
}

\author{
Paweł Terefenko $^{1, *(1)}$, Dagmara Zelaya Wziątek ${ }^{2}$, Sagi Dalyot ${ }^{3}{ }^{(0)}$, Tomasz Boski ${ }^{4}$ \\ and Francisco Pinheiro Lima-Filho ${ }^{5}$ \\ 1 Institute of Marine and Coastal Sciences, Faculty of Geosciences, University of Szczecin, Mickiewicza 18, \\ 70-383 Szczecin, Poland \\ 2 Faculty of Geodesy and Cartography, Warsaw University of Technology, pl. Politechniki 1, \\ 00-661 Warszawa, Poland; dagmara.zelaya@gmail.com \\ 3 Faculty of Civil and Environmental Engineering, Technion-Israel Institute of Technology, \\ 32000 Haifa, Israel; dalyot@technion.ac.il \\ 4 CIMA - Centro de Investigação Marinha e Ambiental, Universidade do Algarve, Campus de Gambelas, \\ 8005-139 Faro, Portugal; tboski@ualg.pt \\ 5 Departamento de Geologia Universidade Federal do Rio Grande do Norte, Campus Universitario, \\ Natal, RN 59078-970, Brasil; pinheiro@geologia.ufrn.br \\ * Correspondence: pawel.terefenko@usz.edu.pl; Tel.: +48-91-444-2354
}

Received: 5 July 2018; Accepted: 23 July 2018; Published: 24 July 2018

\begin{abstract}
Formation of notches is an important process in the erosion of seaside cliffs. Monitoring of coastal notch erosion rate and processes has become a prime research focus for many coastal geomorphologists. Observation of notch erosion rate considers a number of characteristics, including cliff collapse risk, distinction of historical sea levels, and recognition of ongoing erosional mechanisms. This study presents new approaches for surveying and classifying marine notches based on a high-precision light detection and ranging (LiDAR)-based experiment performed on a small region of a coastal cliff in southern Portugal. A terrestrial LiDAR scanner was used to measure geometrical parameters and surface roughness of selected notches, enabling their classification according to shape and origin. The implemented methodology proved to be a highly effective tool for providing an unbiased analysis of marine morphodynamic processes acting on the seaside cliffs. In the analyzed population of voids carved into Miocene calcarenites in a coastal cliff section, two types of notch morphology were distinguished, namely U-shaped and V-shaped. The method presented here provides valuable data for landscape evaluation, sea-level changes, and any other types of analyses that rely on the accurate interpretation of cliff morphological features.
\end{abstract}

Keywords: coastal notches; LiDAR; notch formations; coasts; coastal cliffs; monitoring

\section{Introduction}

Monitoring of coastal zones, as well as identification of forcing processes acting in such zones, has become a prime research focus for many coastal geomorphologists. This is particularly the case for many countries and regions where coastal land and the infrastructure built in coastal regions are subject to hazards such as storm surges and erosion [1-3].

Along rocky coasts, notches (undercuts in a vertical cliff profile) are probably the most significant and visible manifestation of cliff erosion representing ongoing processes or their historical activity. Notches are formed by the constant and long-term action of physical weathering, involving the mechanical action of waves, wind, and dissolution of sand, pebbles and rock by chemical weathering. These processes frequently occur simultaneously, which makes it difficult to distinguish individual 
processes based on a single characteristic. For this reason, both physical and chemical weathering are included in the single term "sea corrosion" [3]. However, each of these weathering processes results in different notch formations indicative of their further development, and for this reason it is important to distinguish between these two types of weathering processes during notch monitoring. In previous studies, notch identification and classification were determined on the basis of field observations [3-6]. Measurements of notch dimensions are generally taken with a rangefinder or measurement pole, whereas for cliff sites with difficult access, notch shapes are recorded using in situ methods. Locations of notches in such studies are recorded using a differential Global Positioning System (GPS) or are derived from topographic maps and aerial photos when notches were inaccessible. Island notch data collection is now frequently accompanied by underwater cliff observations through snorkeling surveys [7].

Although there have been significant advances in the interpretation of the behavior of coastal systems [8,9], wider knowledge of the mechanisms of erosion is still required to advance our understanding of coastal process and potential hazards. Recent studies explore a newly identified trend of the global disappearance of tidal notches [7]. In light of such important discoveries, development of precise and accurate methodologies for notch identification and genetic type evaluation is crucial. During the last decade, new remote sensing techniques such as light detection and ranging (LiDAR) have been applied to topographic surveys [10] and to the monitoring of coastal processes $[2,11]$. LiDAR is a "laser-based survey technique allowing rapid and accurate collection of large amounts of topographic data" [11] from three possible platforms: satellite, airborne, and terrestrial. In all of these platforms, a common scanning technique, "time-of-flight", is used. In this technique, a LiDAR scanner emits a narrow, high-frequency laser beam in the direction of the scanned object, thereby obtaining a 3-dimensional (3D) coordinate $(x, y, z)$ point data by measuring the distance, reflection time, angle, and the intensity of the returned signals. Data are received by mirrors rotating around different axes.

Traditional methods of identifying genetic notch type and shape directly in the field rely on the experience and knowledge of members of a field team [6]. Practical training in notch field characterization requires multiple field campaigns, and does not always ensure accurate results. In more complex cases, notch shape descriptions that are based on dimension measurements cannot be performed, due to cliff inaccessibility or rapid and significant changes of tides [3]. Accuracy of the traditional "in situ" methods relies on a combination of different techniques, and sometimes dangerous conditions can result in measurement errors of $\pm 20 \mathrm{~cm}$. As applied in the presented analysis, LiDAR technology surpasses all traditional methods from every possible aspect. Using LiDAR, it is possible to obtain accurate measurements of terrain surfaces with an accuracy of $\pm 6 \mathrm{~mm}$, even for the physically inaccessible sections of a cliff $[10,11]$. Moreover, additional advantages of using a LiDAR scanner include data storage capabilities and the possibility of geo-referencing the entire dataset. This allows for a variety of types of analyses that can incorporate other geographic datasets [11]. A significant advantage of LiDAR data collection over traditional techniques is related to time limitations. Coast lines are extremely dynamic environments. To track cliff changes as well as the processes of modifications, data must be collected frequently and over a consistent time interval. Data collection using classic field methods is a long and laborious process, which in case of extensive research areas do not provide the required results [3,11].

The essential high-accuracy 3D spatial data can be also gathered with different remote sensing methods such as structure-from-motion (SfM) photogrammetry or video imaging. New techniques used to acquire data with greater precision especially for landforms of varied scale such as coastal cliffs, shore platforms, pocket beaches, marine caves, or marine notches located in the inaccessible areas, open a range of possibilities to analyze coastal areas geometry (for useful overviews see, for example [12-14]).

The present contribution aims to elaborate on a methodology of LiDAR data processing to evaluate coastal genetic notch types. For this purpose, a workflow using data collection, interpolation, raster analysis, and morphological parameterization of the notch profiles has been suggested. 


\section{Materials and Methods}

\subsection{The Study Area}

A $200 \mathrm{~m}$-long stretch of coastline in the central part of the Algarve region, southern Portugal, was chosen for the study. The area is geomorphologically diverse, and includes coastal cliffs, pocket beaches, marine caves, and marine notches. The studied cliff face is located in a sheltered position with respect to the dominant direction of waves approaching the coast, and is carved into bioclastic limestones and sandstones of the intensely karstified Lagos-Portimão Formation (LPF) [15-17]. The Lagos-Portimão Formation (LPF) is the most prominent Miocene unit in western Algarve, unconformably overlying Carboniferous, Jurassic, and Cretaceous rocks [18]. Coastal palaeokarst in the area were fossilized during the Pliocene and Pleistocene Epochs [15-19].

The southern Algarve coastline is a highly energetic environment with an average significant wave height of $1.3 \mathrm{~m}$ and a period of $6.6 \mathrm{~s}$. In the study area, there are primarily two directions of wave propagation that account for $94 \%$ of wave impacts, WSW (71\%) and ESE (23\%) [20]. Tides have a semidiurnal cycle with an average height of $2 \mathrm{~m}$. Extreme tide heights occur during spring tides, with maximum and minimum tide heights of $3.82 \mathrm{~m}$ and $0.64 \mathrm{~m}$, respectively [17]. The study area of the Carvalho pocket beach is located between Benagil and Anfanzila (Figure 1). The western cliff of the beach is $198 \mathrm{~m}$ long and approximately $27 \mathrm{~m}$ high, and contains small natural caves, artificial corridor-like structures, and notches (Figure 2). Identification of a variety of structures, including the various types, sizes, and shapes of notches, indicates that the selected cliff area is well suited to an investigation of notch form and genesis. Also, the diversity of coastal erosion structures confirms that the selected cliff is affected by both physical and chemical weathering. The geometry of Carvalho pocket beach favors observations by LiDAR, by allowing comprehensive examination of the western cliff (Figure 1).

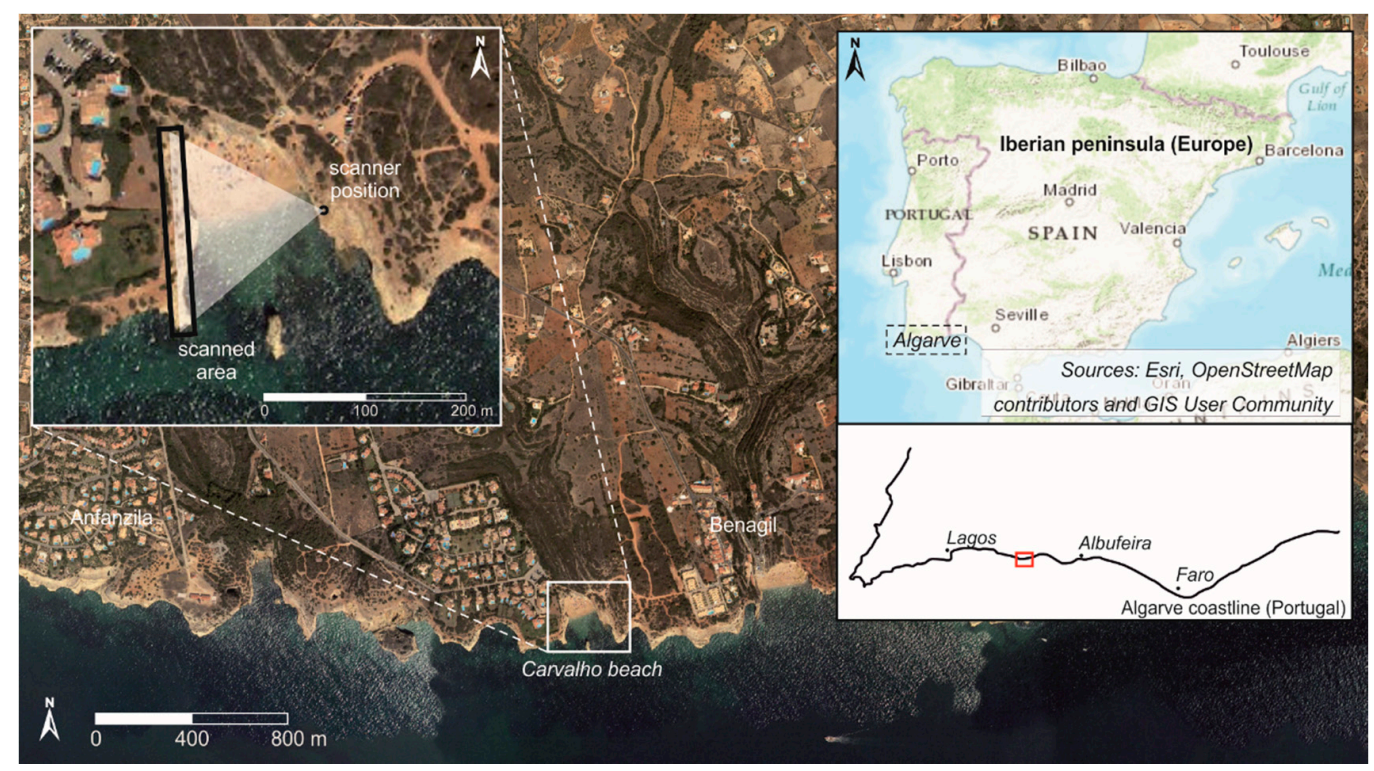

Figure 1. Location of the study area and scanner position (zoomed map image) during the site survey. Carvalho Beach is located within the white frame, between Benagil and Anfanzila. 


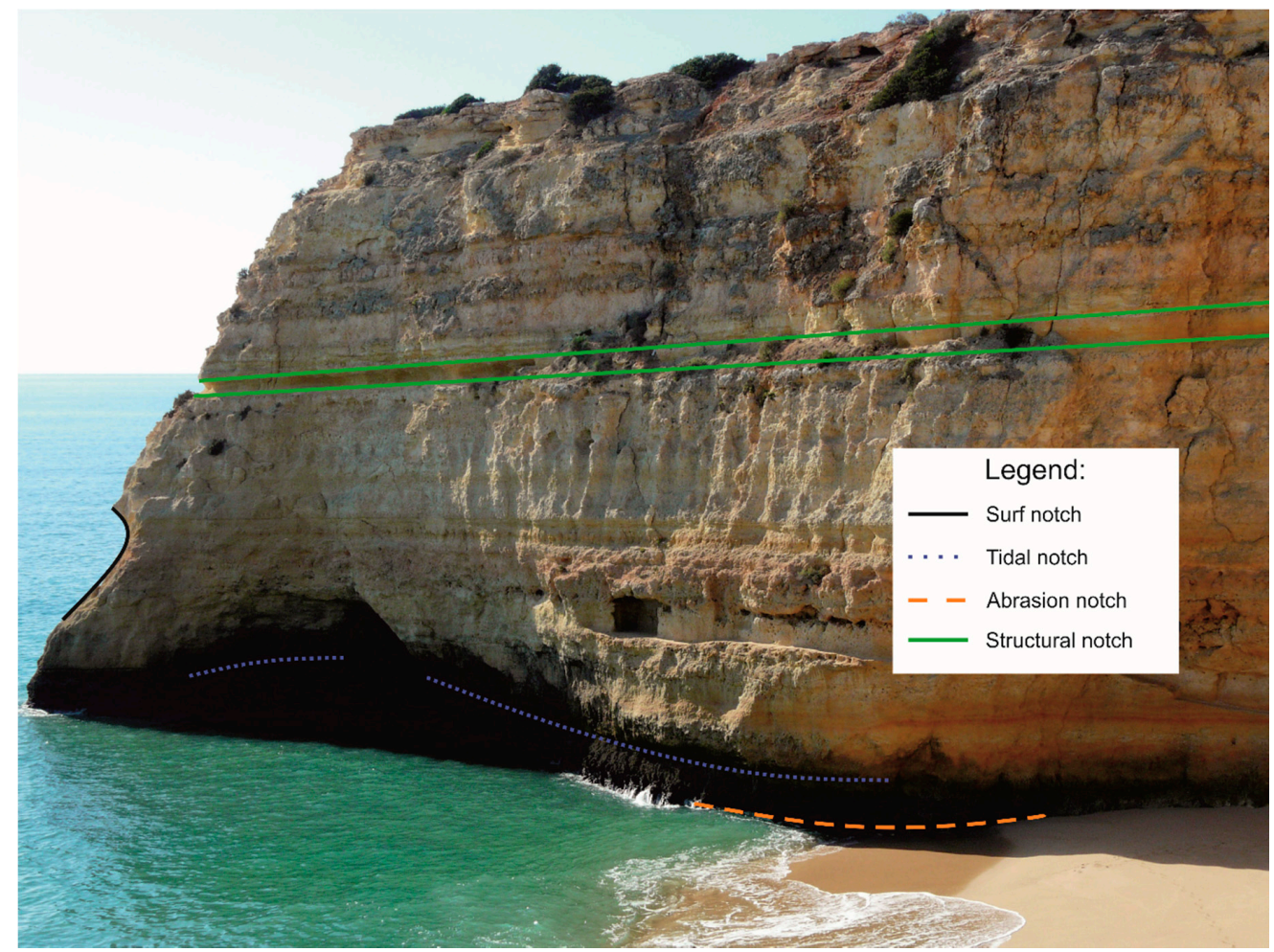

Figure 2. The western cliff of Carvalho beach illustrating the main identified notch types.

\subsection{Notch Classification}

Although there have been significant advances in the understanding of the behavior of coastal systems [8,21,22], wider knowledge of the mechanisms of erosion is still required to better inform our understanding of coastal process and potential hazards. Along rocky coasts, notches (undercuts in the cliff vertical profile) are probably the most significant and visible manifestation of cliff erosion. Notches of all kinds are the main cause of cliff destabilization and of the final phase of cliff collapse [4,23-26]. For this reason, monitoring the changes in notch geometry and identifying the erosional mechanisms of notches play a key role in the assessment of the risk of cliff failure.

Coastal notches can be defined as indentations formed by the constant and long-term action of seawater, which causes cliff degradation in a two-type erosion process: (1) physical erosion, involving the mechanical action of waves, wind, sand, and pebbles; and (2) chemical erosion, involving rock dissolution. These processes occur mostly simultaneously, which makes it difficult to distinguish individual processes based on a single characteristic.

Based on a literature review, it was found that coastal notches tend to be defined according to their genetic type. For the purposes of this study, notch classification was based on the definitions offered by Pirazzoli [3], and consist of four basic types:

- abrasion notches created by the mechanical action of sand and pebbles,

- structural notches generated by the mechanical action of the wind (mechanical weathering),

- surf notches linked to surf and spray action,

- tidal notches generated by mechanical and/or chemical erosion of the sea water.

Diversity of eroding forces influences notch location and structural characteristics. In order to simplify the understanding of these relationships, the genetic types of notches were classified during field observations according to three factors (Table 1), including elevation relative to low and high tide, shape (Figure 3), and texture [6]. 
Table 1. Notch genesis classification criteria [6].

\begin{tabular}{ccccc}
\hline & & \multicolumn{2}{c}{ Notch Type } & \\
\cline { 2 - 5 } & Tidal & Surf & Abrasion & Structural \\
\hline Elevation & $4 \mathrm{~m}$ above low tide level & $1.5 \mathrm{~m}$ above high tide level & - & - \\
Shape & Relatively symmetrical & Asymmetrical or hook-like shape & Symmetrical & Symmetrical \\
Texture & (U or V) & - & Smooth & Smooth \\
\hline
\end{tabular}
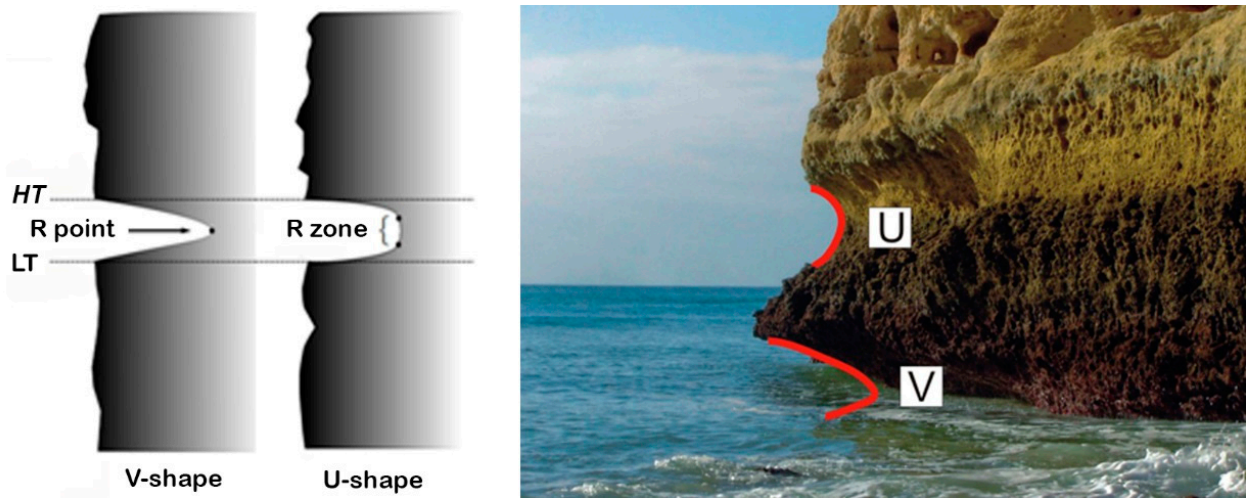

Figure 3. Sketch of U- and V-shape notches (adapted from [6]) with a field example (photo: P. Terefenko). Notch identification on the cliff surface as well as further evaluation of notch shape was performed based on cliff hillshade and contour maps. Notches were located on cliff areas when two basic criteria were fulfilled. These criteria are detection of a sudden slope change as indicated by a dense isoline, and an observed high shade value of the hillshade raster. For this analysis, a shade color value of 180 was assigned as the threshold.

Evaluation of notch shape was performed based on notch geometrical parameter evaluation. Initial profiles of wave cut notches were commonly symmetrical with characteristic points developed according to characteristic sea levels (Figure 4) [3].

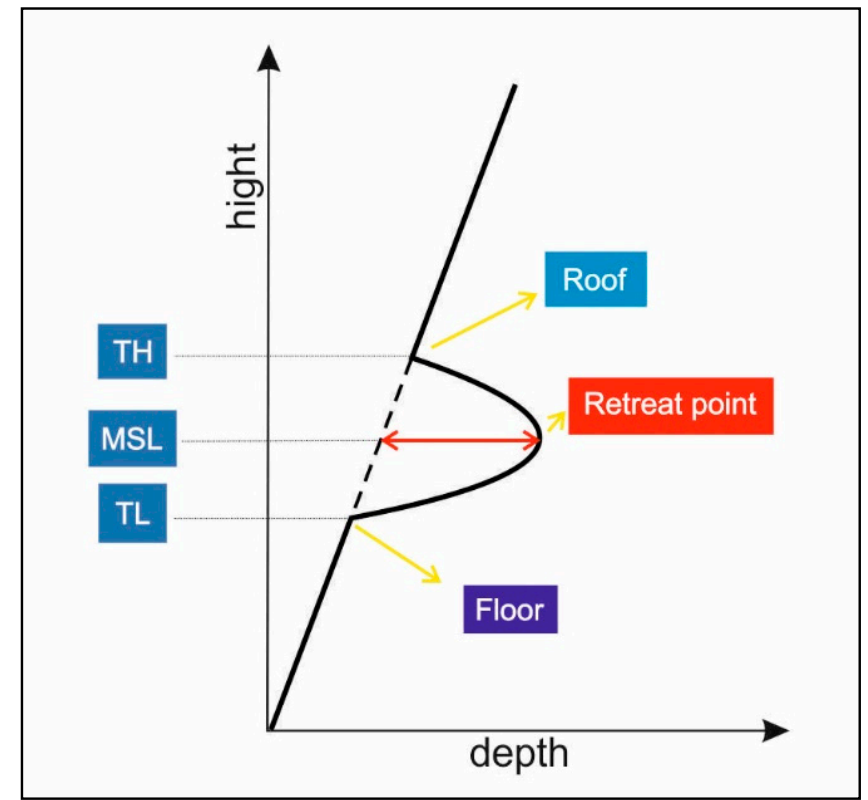

Figure 4. Sketch of initial tidal notch profile with characteristic points. TH-high tide level, TL-low tide level, MSL-mean sea level. 
The most crucial characteristic points in a notch profile are:

- notch base (floor) corresponding to low tide level,

- retreat point (or retreated zone), represented by the deepest point,

- notch roof, corresponding to high tide level.

For notch shape evaluation, two basic models of notch shapes were parameterized according to the observed geometrical relationships. A U-shape notch is one in which an undercut notch retreating point/zone height extends $25 \%$ of the total notch height. In contrast, a V-shape notch is one for which the retreating point/zone does not extend $25 \%$ of the total notch height.

To characterize morphologic attributes of the notches, notch parameter estimation was performed. Calculations were applied to notch profile graphic plots of the raster terrain surface, as depicted in Figure 5, to determine:

- notch retreating zone range: the deepest notch value plus a threshold value set to be $10 \%$ of the notch depth,

- notch retreating point/zone height: height of the notch retreating zone range,

- total notch height: extent of the notch height measured from the lower notch boundary to the notch roof.
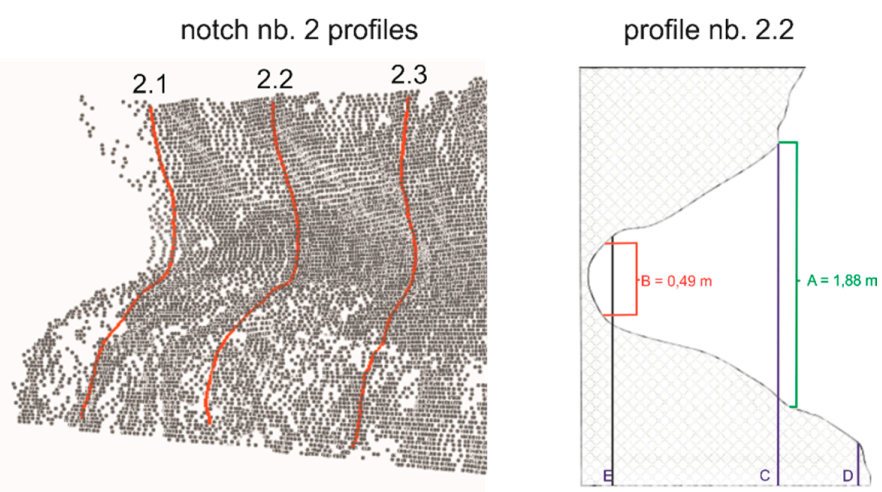

Figure 5. Example of a three-dimensional (3D) point cloud with derived cliff profile (left), and schema of the notch parameter estimation derived from its geometry (right). A-notch height, B-height of the retreating zone, $\mathrm{C}$ and $\mathrm{D}$-maximum and minimum notch depth points, $\mathrm{E}$ - upper limit of the retreating zone depth. For notch location see Figure 6.

\subsection{LiDAR Methodology}

Sea cliffs belong to a type of terrain that is difficult to capture by laser scanner. Therefore, the use of LiDAR data to represent coastal cliff surfaces with satisfactory accuracy is one of the principal challenges and concerns of scientists monitoring the coast [11]. Because of their low vertical accuracy, satellite data are not commonly used for surveys of cliff coasts in a detailed scale, and for that reason, were not considered for the present study. However, both airborne and terrestrial laser scanner data are found to be highly accurate, therefore, frequently used [27].

Airborne LiDAR surveys have one important advantage in that laser scanning can be done from the sea side. This allows data collection from positions that are otherwise inaccessible by terrestrial LiDAR and traditional methods, and assures that suitable data coverage is obtained [10,11]. However, data accuracy is usually poorer due to a high laser beam incident angle that does not allow for sufficient data collection. In addition, to obtain data with high vertical accuracy and at the same time penetrate all notch depths, the airplane needs to fly at very low altitudes and almost perpendicular to the cliff itself. In addition, airborne measurements are quite expensive and become cost effective only when implemented in large scale campaigns [11]. 
Terrestrial LiDAR data has better vertical accuracy due to the potential of scanning notch base positions over a small distance and perpendicular to the cliff. However, problems with efficient laser beam incidence angle occur. Another seemingly problematic aspect of terrestrial LiDAR is data resolution, which differs from the airborne LiDAR platform because of a laser footprint and smaller point spacing. This fact can be taken as an advantage since it allows for the collection of more detailed data. However, if more detailed point spacing is combined with data at high point spacing, loss of small terrain structures may occur [11].

A major problem associated with LiDAR surveys of cliff areas is associated with vertical measurement accuracy. Vertical errors are strongly correlated with increasing slope. It has been shown that in case of cliffs with slope greater than $55^{\circ}$, vertical error reaches a critical value (root mean square (RMS) equal to $0.58 \mathrm{~m}$ ), whereas for a beach with inclination ranging between $1-10^{\circ}$, the RMS error decreases to a value of $0.09 \mathrm{~m}$ (Table 2) [11,17].

Table 2. LiDAR vertical accuracy assessments as function of cliff slope [11].

\begin{tabular}{cccccc}
\hline $\boldsymbol{\beta}$ & Zone & Mean & Min. & Max. & RMS \\
\hline $0-1^{\circ}$ & Tidal flat & 0.06 & 0.00 & 0.63 & 0.09 \\
$1-10^{\circ}$ & Beach & 0.11 & 0.00 & 0.64 & 0.15 \\
$10-20^{\circ}$ & Dune & 0.18 & 0.01 & 0.65 & 0.24 \\
$20-55^{\circ}$ & Bluff & 0.35 & 0.02 & 1.26 & 0.44 \\
$55-90^{\circ}$ & Cliff & 0.30 & 0.01 & 1.81 & 0.58 \\
\hline
\end{tabular}

The correspondence between slope and vertical RMSE has been described as a general linear relationship [11]:

$$
\Delta z=A+(B \beta)
$$

where $A$ represents the maximum systematic vertical error, and $B$ is an undetermined coefficient, inferred to be a function of terrain slope and horizontal systematic laser error.

Additional reasons of possible vertical inaccuracy are related to the presence of vegetation, altitude of the measuring platform (especially important in case of airborne LiDAR), and transformation of the laser data into a local coordinate system. Horizontal accuracy was found to be dependent on LiDAR positioning and its spatial resolution [11].

Even small errors in LiDAR calibration were found to increase distance measurements, resulting in significant observation errors [10]. In unfavorable weather conditions, the laser encounters more obstacles, which can increase its reflectivity and as a result will increase data error. Additionally, refraction of the laser beam by water droplets from sea sprays, rain, snow, or fog will reduce data accuracy $[10,11]$.

The complexity of a cliff has a strong influence on laser beam reflection. Since reflectivity of the surface increases with roughness, the laser beam is strongly diffused in very complex parts of a cliff. As a result, the beam does not return to the scanner, or the return signal provides inaccurate values.

The above-mentioned accuracy limitations of a LiDAR survey occur mainly due to the positioning of the LiDAR platform during laser scanning. The platform position determines the ability of a laser beam to penetrate a notch. For this reason, the parts of the cliff, which can be scanned with satisfactory accuracy depend on the notch dimension coefficient $C$ :

$$
C=\frac{b}{a}
$$


where $a$ represents height and $b$ represents depth. The laser beam incident angle $i$, is a function of the platform altitude, $H$, and the distance between the LiDAR nadir and notch position $d$, whereas $h$ represents the elevation of the lower overhang break line and $b^{\prime}$ is the effective survey depth [11]:

$$
\tan (i)=\frac{d}{H * a * h}=\frac{b^{\prime}}{a}
$$

Complete notch penetration by the laser is possible only if two major requirements are fulfilled. First, the effective survey depth must be equal to or larger than the notch depth:

$$
b^{\prime} \geq b
$$

and second, the laser beam incident tangent angle is equal to or higher than the notch dimension coefficient:

$$
\tan (i) \geq C
$$

In order to establish a methodology of LiDAR data processing to evaluate coastal genetic notch types, a terrestrial LiDAR was employed. Terrestrial LiDAR provides low cost, highly accurate data with readily available equipment. Laser scanning was provided with the assistance of the University of Algarve (Faro, Portugal). A terrestrial LiDAR survey was conducted in July 2011 using a Leica Scan Station 2. Specifications of this instrument are described in Table 3. During the survey, the scanner was positioned on the top of the eastern cliff (Figure 1), and fixed to a tripod. Due to the complex geomorphology of the area, scanner location was chosen based on the visibility criteria. The east cliff side was the only sector allowing data collection with sufficient angle. From this configuration, a real-color point cloud representing the eastern cliff side/face was obtained acquiring approximately 100 points per $\mathrm{m}^{2}$, with an estimated vertical accuracy better than $10 \mathrm{~mm}$. The generated 3D point cloud was aligned to a real-world coordinate system on the basis of a set of seven known ground-control points (GCPs), from which four were used for a georeferencing process. For point cloud verification, a subsequent analytical procedure was applied for a second scan realized from another scan station located at a distance of $50 \mathrm{~m}$. The remaining three GCPs were used as control spots to calculate the vertical offset between the point clouds, which varied from 3 to $9 \mathrm{~mm}$. From this configuration, a real-color point cloud representing the eastern cliff side/face was obtained. For defining subsequent analytical procedures, three cliff areas of interest were selected (Figure 6).

Table 3. Leica Scan Station parameter specifications.

\begin{tabular}{cc}
\hline Scanner Parameters & Parameter Value \\
\hline Wavelength & $532 \mathrm{~nm}$ \\
Field of view & Horizontal $360^{\circ}$ \\
Maximum scan distance & Vertical $270^{\circ}$ \\
Maximum scanning speed & $300 \mathrm{~m}$ \\
Angular resolution (horizontal and vertical) & $5000 \mathrm{pts} / \mathrm{s}$ \\
3D scan precision & 0.0023 \\
\hline
\end{tabular}




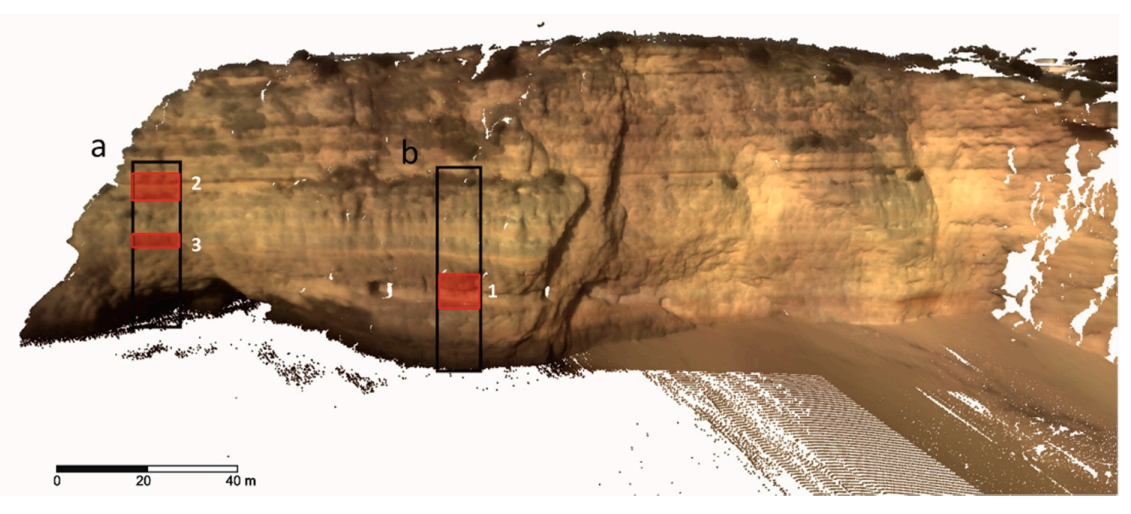

Figure 6. Real-color point cloud from a light detection and ranging (LiDAR) survey of the western cliff face. Regions a and b contain voids selected for further testing of the proposed method for surveying and classifying coastal notches. Numbers 1-3 represent approximate locations of analyzed notches.

\section{Results}

The main product of a laser scanning survey is a high resolution point cloud, obtained by measuring with high accuracy the distance of a mesh of points on the object $[10,11]$. With the aim of keeping all the original information, the LiDAR point cloud was used for analysis of notch parameters. Concurrently, several high resolution digital surfaces created from the point cloud were also used for notch parameterization in order to enable the analysis of obtained datasets originally in classic GIS software without the need of sophisticated extensions or software dedicated only to terrestrial LIDAR or point cloud analysis. In this approach, a data loss was accepted in favor of creating a method of bigger applicability in practice.

Due to the large number of points obtained from the original single laser scan, three cliff areas of interest were selected for subsequent analytical procedures (Figure 5). Data were processed in an ArcGIS environment using the applications ArcMap, ArcScene, and LP360.

Digital surfaces were generated using both the triangulated irregular network (TIN) and interpolation-based raster methods. Three methods of raster interpolation were used: natural neighborhood, inverse distance-weighted with a 12-point radius, and the Kriging model. Applied methods of grid surface interpolation were chosen due to widely available and well developed tools for its further analyses in GIS environments.

In order to minimize the effect of data lost during creating a digital surface from the point cloud, two different raster cell size of 10 and $20 \mathrm{~cm}$ were tested. For final analysis, a $10 \mathrm{~cm}$ raster size was chosen. Within the Kriging method, only $90 \%$ of the original cloud point were used for the interpolation process. The remaining $10 \%$ were used for model cross-validation. On the basis of the normal quantile-quantile (QQ) plot graph, the quantiles of the difference between the predicted and measured values and the corresponding quantiles from a standard normal distribution were analyzed. The points distribution proved that the method used relied on normality.

A comparison of TIN and raster surfaces indicated no significant difference in the coherence of the terrain models generated using the two methods. According to the literature [11,28], grid-based terrain models are a best fit due to a well-developed analysis framework, in cases where further analysis is performed, while TIN surface is a better fit for visualization purposes. TIN surface estimates single locations more robustly than grid; however it is not recommended for producing profiles [11], which is a crucial issue in the notch analysis process. Although the TIN surface was found to be more detailed according to "fitness for purpose" [10], due to limitations of further analyzes and accurate profile preparations, it was decided that the more continuous raster data were more suited for representing the notches. In order to choose the most appropriate surface among the three created raster surfaces, a test was conducted whereby rasters of height differences between the three raster surfaces were generated to identify the area of the cliff surface exhibiting the greatest difference. The analysis showed 
that Kriging interpolation was the most reliable of the three approaches, as it was smooth and had less noise. Based on these results, all further analysis was performed using the raster method through Kriging interpolation.

\section{Genetic Notch Type Evaluation}

Identification of the notch genetic type consisted of three steps: (1) notch identification in the cliff surface; (2) notch shape acquisition; and (3) surface roughness calculation.

Due to specific notch geometry and its concavity, structure identification of notches in the cliff surface was based on the hillshade of the cliff and on the contour map generated using the Kriging interpolation raster method. It was assumed that both contour and hillshade maps would indicate sudden values changes in the notch border. A contour map was generated using a contour interval of 10 and $20 \mathrm{~cm}$ directly from the Digital Surface Model (DSM). After the preliminary notch border identification process, the $10 \mathrm{~cm}$ interval was chosen for further analysis. However, it should be noted that because of the flipping of axes, contour lines did not represent height values, but rather isolines of cliff depth. Accordingly, areas that are convex had higher contour values. Hillshade was produced with azimuth and altitude angles of the light source above the horizon at 45 decimal degrees. It is also worth noting that because the cliff was positioned horizontally as result of the axis flip, shadow angles referred to a horizontal and not a vertical plane.

On the basis of contour map analysis, notches were identified where contour lines (isolines) were very dense. Although contour values did not represent heights, if their density (concentration) was higher than their surroundings, this denoted areas of marked change in both the vertical and horizontal dimensions. Because of this property, both concave and convex areas of marked change were represented by dense isolines. Therefore, further analysis of hillshade for identifying the concave areas was performed, based on a sudden slope change and high shade value of the hillside raster as described in Section 2.2.

In addition to notch elevation, shape and surface texture are used to classify genetic notch type. To classify the shape of a notch as either $\mathrm{U}$ or $\mathrm{V}$ type, specific geometry parameters were determined for the notch profiles as represented in the raster terrain surface. Because of the variation encountered in a notch profile in the lateral direction, several profiles were created for each notch. Final values of total notch depth, average height of the retreat zone, and average notch height were calculated as mean values of these parameters for individual notch profiles.

Intervals between profiles for each notch were set to $1 \mathrm{~m}$. The number of profiles per notch differed depending on notch length. For notch nb.1, five profiles were obtained, whereas for notches nb.2 and nb.3, eight profiles were acquired.

To obtain surface texture, two steps were performed: (1) extraction of the notch area data and (2) surface roughness calculation. Notch surface data were extracted from the raster data by identifying the upper and lower boundaries of each notch based on a combination of slope, hillshade, and contour data (Figure 7). Contours of the final positions of the boundaries were approximate, given the method used to identify them (manual identification using hill shade and isolines). 


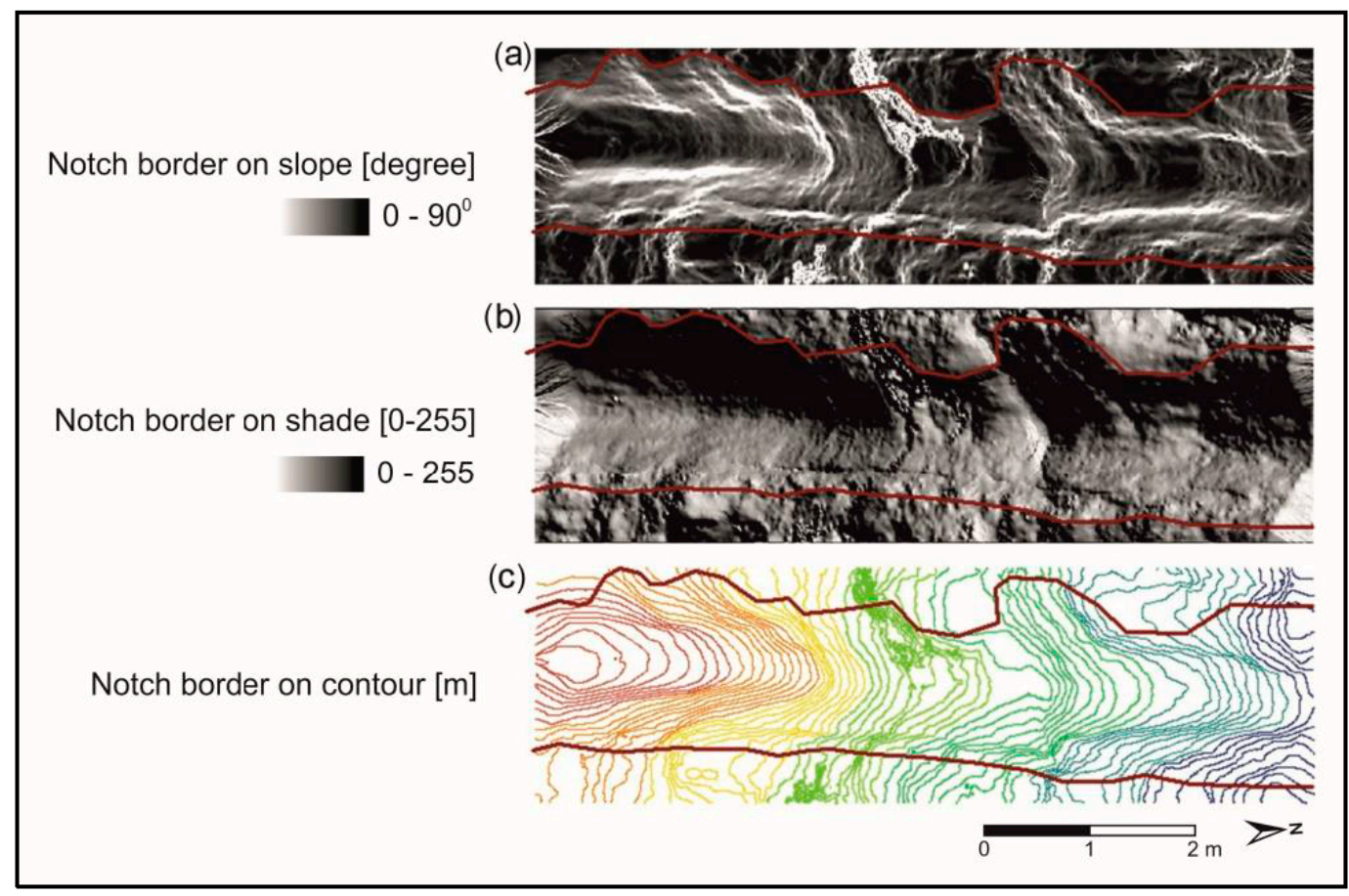

Figure 7. Example of notch boundary identification for notch nb.2. Results based on slope (a); hillshade (b); and contour data (c).

Surface roughness has been described as a standard deviation of the pixel density of the profile-plan curve raster. The profile curve raster represents the curvature of the surface in the direction of the slope, whereas the plan curve raster shows a curvature perpendicular to the direction of slope. By combining these two morphologic attributes (represented as rasters), it was possible to extract and identify values of curvature in both directions, which from a theoretical perspective corresponded to surface roughness. Notch surface roughness was categorized according to statistical standard deviation ranges as smooth, moderately smooth, moderately rough, or porous (Table 4).

Table 4. Criteria for notch surface roughness identification (values of pixel intensity).

\begin{tabular}{cc}
\hline $\begin{array}{c}\text { Standard Deviation of Pixel Density of the Profile-Plan } \\
\text { Curvature Raster Range }\end{array}$ & Surface Roughness Description \\
\hline $0-15.000$ & Smooth \\
$15.000-30.000$ & Moderately smooth \\
$30.000-45.000$ & Moderately porous \\
$>45.000$ & Porous \\
\hline
\end{tabular}

Using the contour and hillshade map analysis and verification of distinguished features on a base of superimposed map of those parameters, three notch areas were identified (Figure 8) within the areas of interest and selected for further testing both on a base of generated digital surface models and the original point cloud. Notch nb.1 was located in the middle part of the northern sector of the cliff (area "b", Figures 5 and $7 b$ ), and notches nb.2 and nb.3 were located in the upper and middle sections of the southern sector of the cliff, respectively (area "a", Figures 5 and 7a). 


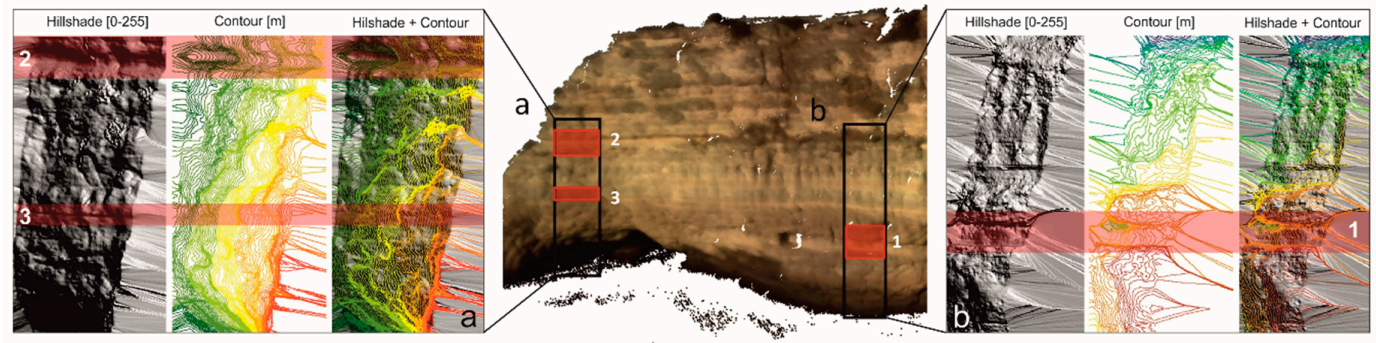

Figure 8. Hill shade, contour, and combined (superimposed) maps of the cliff, and detected notch positions $(\mathbf{a}, \mathbf{b})$. Numbers $1-3$ represent locations of analyzed notches.

The applied methodology enabled the identification of detailed characteristics of the notches. Notches nb.1 and nb.2 were U-shaped whereas nb. 3 was V-shaped. Although all notches conformed to the general shape classification scheme, notch nb.1 had a rectangular morphology, as opposed to circular shapes exhibited by nb.2 and nb.3. The established threshold values for notch shape recognition do not take into account the possibility of occurrence of a rectangular form. This fact, as well as the observed regular shape, the almost horizontal slope of the boundaries, and large dimensions (Table 5), led to the conclusion that notch nb.1 represented an unnatural feature. Notch nb.2 was an example of a perfectly symmetrical U-shaped notch (1.88 $\mathrm{m}$ deep and $1.86 \mathrm{~m}$ high). Notch nb.3 had the smallest dimensions ( $0.4 \mathrm{~m}$ deep and $0.25 \mathrm{~m}$ high), and if it were not for its continuity in the horizontal direction, it would not have been detected as a notch.

Table 5. Summary of notch profiles. Parameters acquired on the basis of point cloud (A) and DSM (B).

\begin{tabular}{ccccccc}
\hline Notch Number & 1A & 1B & 2A & 2B & 3A & 3B \\
\hline Average depth $(\mathrm{m})$ & 1.08 & 1.2 & 1.92 & 1.88 & 0.35 & 0.38 \\
Threshold value for retreat zone height $(\mathrm{m})$ & 0.11 & 0.12 & 0.18 & 0.188 & 0.06 & 0.04 \\
Average height of retreat zone (m) & 0.49 & 0.55 & 1.24 & 1.16 & 0.07 & 0.055 \\
Average notch height (m) & 1.66 & 1.75 & 1.88 & 1.86 & 0.29 & 0.25 \\
Retreat zone maximum percentage of total & 30 & 31 & 64 & 62 & 20 & 22 \\
notch height (\%) & $\mathrm{U}$ & $\mathrm{U}$ & $\mathrm{U}$ & $\mathrm{U}$ & $\mathrm{V}$ & $\mathrm{V}$ \\
Notch shape & & & & & &
\end{tabular}

On the basis of the values of standard deviation as well as the value range of the profile-plan curvature raster, notch surface roughness values for the three notches were determined as follows: notch nb.1, moderately smooth; notch nb.2, smooth; and notch nb.3, moderately porous. According to the mechanisms of notch evolution, interior regions of notches created by wind or sand/pebble action were completely smooth, whereas interior parts of notches of marine origin (tidal and surf notches) were rougher.

Notch nb.1, with a moderately smooth surface, could potentially be classified as an abrasion or structural notch. However, because of the height of the notch on the cliff profile, its origin could not be satisfactorily explained as either of these two types. Also, structural notches have symmetric, U-shaped forms and, in typical conditions, would not attain a size as that presented by notch nb.1. The atypical combination of a moderately smooth surface and a rectangular, almost symmetrical notch located in the middle of a cliff suggests that this notch represented a discontinuity of anthropogenic origin in the cliff profile. The location of the notch as identified on photographs (Figures 2 and 6) appeared to be part of a human-made feature engraved in the cliff. Site inspection confirmed a non-natural origin for the detected notch. It proved to be a man-made corridor carved into the cliff wall, created as a tourist attraction accessible form the pocket beach.

Notches nb.2 and nb.3 were considered to be naturally occurring. Notch nb.2 had a smooth surface and accordingly could potentially be classified as an abrasion or structural notch. Due to its 
smooth surface and location on the upper part of the cliff, notch nb.2 was identified as a structural notch. Notch nb.3 had a moderately porous surface and should therefore be classified as a tidal notch. However, the small dimensions of this notch and its height above the intertidal zone did not support this classification. Two possible scenarios could apply: (1) the notch is tidal and developed at mean sea level (MSL), and subsequently the cliff section was tectonically uplifted or MSL decreased, or (2) the notch is structural and has developed by chemical reaction with sea spray in a rock layer of lower chemical resistance compared with the surrounding material.

\section{Discussion}

Generation of coastal notches is an important component of the erosion process of seaside cliffs. Notch location on the cliff face as well as their shape have previously been determined on the basis of visual observations [3,6,24] or remote techniques like Structure for Motion photogrammetry methods [14]. Although the terrestrial laser scanner may experience some problems for delivering 3D point data necessary to identify small undercuts and those near the sea [29,30], this work demonstrates that it does improve not only the identification process, but also characterization of notch detail parameters, and finally recognition of their genetic types. It should be remembered though that Terrestrial Laser Scanner is limited mainly in determination of a proper scanner position, which may influence the possibility of performing correct measurements.

Even though there are several limitations for using LiDAR technology on cliff zones, acknowledgment of the required recommendations and precautions can ensure that highly reliable and detailed data can be obtained. Thus, monitoring the dynamics of coast lines can become (to some extent) an easy, continuous, reliable, and very informative process. Another advantage of using laser scanning is for safety reasons, in that complex data can be obtained safely from a considerable distance $[10,11]$.

In the presented work, the point cloud spatial data was verified with GCPs and confirmed by a second scan realized from another scan station located at a distance of $50 \mathrm{~m}$. The precision of the measurements were decreased, as the digital surface was used for analysis instead of original 3D point cloud. Such an approach was a compromise to use a high resolution model with some data loss, in favor of creating a method of bigger applicability in practice, though the interpolated digital surface was prepared using the Kriging method where 10\% of the original points were used for a cross-validation model. Statistical analysis of point distribution on the generated surface evidenced that the method used relies on normality.

As in Kogure and Matsukura [31], it has been proven that precise 3D geometrical characteristics of coastal cliff and its features are crucial in the determination of critical notch depths. For the failure of limestone cliffs, we compared the results of this study to research conducted in the project "GIS analysis of features controlling coastal morphology of Algarve (Portugal)" funded by the National Science Centre, Poland. In that project (referred to here as the UMO project), where numerous identifications of notch occurrence and processes were made on the same cliff as studied in the present paper.

Field work conducted during the UMO project revealed one tidal U-shaped notch recognized in the lower part of the northern sector of the analyzed cliff profile. This notch was not detected during this study due to noise in the LIDAR data set for that part of the cliff, resulting from signal refraction from the water or platform surface. For this reason, future acquisition of LiDAR imagery should be performed during the hours of low tide to generate more data for the cliff base.

In the profile of the southern sector of the cliff, two notches were recognized in the UMO project: one U-shaped tidal notch in the lower part of the cliff, and a structural notch in the upper section of the cliff. This second cavity was detected during LiDAR data analysis and was also classified as being of a structural type. The lower tidal notch was not identified by LiDAR for the same reason as described above for the northern sector of the cliff. However, notch nb.3 detected by LIDAR data was not recognized in the UMO project because of its small size and difficulties in cliff accessibility. 
Notch shape was identified here using measures of notch geometry, including notch height, notch depth, height of the retreat zone, and retreat zone range. All these parameters were measured from notch topographic profiles. The main criterion for the evaluation of notch shape was based on whether the retreat zone height exceeded $25 \%$ of the total notch height. The results demonstrate that the model for notch shape classification works better than traditional methods, which are based on inaccurate values or assumptions of shape. However, although the threshold (criterion) values established for estimates of notch parameters yielded the expected results, further work needs to be conducted on setting criterion values of additional notch parameters to help distinguish natural notches from anthropogenic features. Moreover, further work could investigate the modification of criterion values for the identification of notch surface roughness according to the resistance of the cliff rocks to erosion, rather than using relative values estimated from the raster.

Classification of notch type based on surface roughness is difficult using traditional techniques. In a field survey, the calculation or even qualitative assessment of notch surface roughness is often impossible due to the height of the notches on a cliff. In such cases, genetic notch type is determined by its shape and/or vertical position in the cliff profile: if the notch is $U$ shaped and is located in the upper part of the cliff, it is assumed to be of a structural type. However, tectonic uplift of cliffs can expose tidal notches at heights expected for structural notches. This possibility of discovering tidal notches at relatively high positions up a cliff can be useful in the studies of past sea levels where the geochronological context is established [5]. In such cases, results from LiDAR may prove of great value because the information about the interior surfaces of notches becomes available and a classification can be made based on shape and surface roughness. Such information and classification could provide constraints on landscape evolution at both local and regional scales. In particular, by being able to distinguish between the various types of notches, the method presented here should be able to provide constraints on models of sea level change and/or tectonic uplift in cases where such models rely on the accurate interpretation of cliff morphological features.

By comparing the results achieved from the analysis of LiDAR datasets generated in the present study with those of the UMO project, it was found that the terrestrial LiDAR survey was more accurate than visual field descriptions. However, for achieving the most detailed and precise results, data should be obtained through the integration of airborne LiDAR data with terrestrial LiDAR data or should be supported with complementary dataset collected with the use of UAV platforms. There are already examples of coastline surveys where airborne LiDAR data have been used to fill gaps in data collected using LiDAR terrain surveys [30]. This solution is desirable because both satellite images and airborne photos provide an overview of the area, which, in conjunction with sequences of rapid changes captured by terrestrial LiDAR, would provide a comprehensive model of such changes. Furthermore a comparison between precision of TLS and SfM photogrammetry methods would be desirable as it was reported that the SfM approach reduces data acquisition time [32].

\section{Conclusions}

A number of analyses performed with an organized high-precision LiDAR-based method for surveying and classifying coastal notches tested on the coastal cliff in Algarve region have led to the following conclusions:

1. The LiDAR technique appears to be more reliable than traditional visual methods, due to better resolution unaffected by illumination, color contrasts, and observer-related subjective factors. Traditional field methods, which require an experienced professional $[3,6]$, provide results that are often very generalized and less detailed, particularly for the inaccessible parts of a cliff.

2. Even though notches may in some cases be classified with the same result using traditional descriptive methods and LiDAR data, it is clear that LiDAR provides more detailed information about erosional cavities (including their shape, roughness, and symmetry) that can be analyzed multiple times by various field teams and with different techniques. 
3. LiDAR data allow changes in notch parameters to be tracked along the full length of a notch, whereas traditional methods measure at most several notch profiles to describe the properties of a notch that may extended hundreds of meters along a cliff.

4. To collect proper data that will allow tidal notch detection, LiDAR surveys need to be conducted during the lowest spring tides, as the greatest challenge for the LiDAR-based approach concerns the surveying and DSM mapping of tidal notches, which are located in basal parts of the cliff and are therefore affected by signal refraction at the water surface.

5. The boundary conditions presented in this study are valid in general and can be implemented worldwide on coastal cliffs.

Author Contributions: This research was mainly formulated and designed by P.T. and D.Z.W. F.P.L.-F., P.T. and T.B. performed the field experiments. P.T. and D.Z.W. wrote the manuscript. S.D. and T.B. reviewed the manuscript and provided comments.

Funding: This research was funded by the National Science Centre grant number UMO-2015/17/D/ST10/02191.

Acknowledgments: This study was partially supported by the National Science Centre, Poland, through the project "Coastal cliffs under retreat imposed by different forcing processes in multiple timescales-CLIFFREAT", project number UMO-2015/17/D/ST10/02191.

Conflicts of Interest: The authors declare no conflict of interest.

\section{References}

1. Ferreira, Ó.; Ciavola, P.; Armaroli, C.; Balouin, Y.; Benavente, J.; Del Río, L.; Deserti, M.; Esteves, L.S.; Furmanczyk, K.; Haerens, P.; et al. Coastal Storm Risk Assessment in Europe: Examples from 9 study sites. J. Coast. Res. Spec. Issue 2009, 56, 1632-1636.

2. Paprotny, D.; Terefenko, P. New estimates of potential impacts of sea level rise and coastal floods in Poland. Nat. Hazards 2017, 85, 1249-1277. [CrossRef]

3. Pirazzoli, P.A. Marine notches. In Sea-Level Research: A Manual for the Collection and Evaluation of Data; van de Plassche, O., Ed.; Springer: Zurich, Switzerland, 1986; pp. 361-400. ISBN (print) 978-94-010-8370-6. [CrossRef]

4. Andriani, G.F.; Walsh, N. Rocky coast geomorphology and erosional processes: A case study along the Murgia coastline South of Barri, Apulia-SE Italy. Geomorphology 2006, 87, 224-238. [CrossRef]

5. Terefenko, P.; Terefenko, O. Determining the role of exposure, wave force, and rock chemical resistance in marine notch development. J. Coast. Res. Spec. Issue 2014, 70, 706-711. [CrossRef]

6. Wziątek, D.; Vousdoukas, M.V.; Terefenko, P. Wave-cut notches along the Algarve coast, S. Portugal: Characteristics and formation mechanisms. J. Coast. Res. Spec. Issue 2011, 64, 855-859.

7. Furlani, S.; Antonioli, F.; Gambin, T.; Gauci, R.; Ninfo, A.; Zavagno, E.; Micallef, A.; Cucchi, F. Marine notches in the Maltese islands (central Mediterranean Sea). Quat. Int. 2017, 439, 158-168. [CrossRef]

8. Deng, J.; Zhang, W.; Harff, J.; Schneider, R.; Dudzińska-Nowak, J.; Terefenko, P.; Giza, A.; Furmańczyk, K. A numerical approach for approximating the historical morphology of wave-dominated coasts-A case study of the Pomeranian Bight, southern Baltic Sea. Geomorphology 2014, 204, 425-443. [CrossRef]

9. Griggs, G.B.; Trenhaile, A.S. Coastal cliff and platform. In Coastal Evolution: Late Quaternary Shoreline Morphodynamics; Carter, R.W.G., Woodroffe, C.D., Eds.; Cambridge University Press: Cambridge, UK, 1994; pp. 425-450. ISBN 9780521598903.

10. Buckley, S.J.; Howell, J.A.; Enge, H.D.; Kurz, T.H. Terrestrial laser scanning in geology: Data acquisition, processing and accuracy. J. Geol. Soc. 2008, 165, 625-638. [CrossRef]

11. Xhardé, R.; Long, B.; Forbes, D. Accuracy and limitations of Airborne LiDAR surveys in coastal environments. In Proceedings of the IEEE Symposium on Geoscience and Remote Sensing, Denver, CO, USA, 31 July-4 August 2006; pp. 2412-2415.

12. Fonstad, M.A.; Dietrich, J.T.; Courville, B.C.; Jensen, J.L.; Carbonneau, P.E. Topographic structure from motion: A new development in photogrammetric measurement. Earth Surf. Process Landf. 2013, 38, 421-430. [CrossRef]

13. James, M.R.; Quinton, J.N. Ultra-rapid topographic surveying for complex environments: The hand-held mobile laser scanner (HMLS). Earth Surf. Process Landf. 2014, 39, 138-142. [CrossRef] 
14. Ružić, I.; Marović, I.; Benac, Č.; Ilić, S. Coastal cliff geometry derived from structure-from-motion photogrammetry at Stara Baška, Krk Island, Croatia. Geo-Mar. Lett. 2014, 34, 555-565. [CrossRef]

15. Antunes, M.T.; Bizon, G.; Naseimento, A.; Pais, J. Nouvelles données sur la datation des dépôts miocènes de l'Algarve (Portugal) et l'évolution géologique régionale. Ciências da Terra (UNL) 1981, 6, 153-168. Available online: http:/ / hdl.handle.net/10362/1505 (accessed on 11 March 2018).

16. Antunes, M.T.; Pais, J. The Neogene of Portugal. Ciências da Terra (UNL) 1993, 12, 7-22. Available online: http:/ /hdl.handle.net/10362/4509 (accessed on 11 March 2018).

17. Brachert, T.C.; Forst, M.H.; Pais, J.J.; Legoinha, P.; Reijmer, J.J.G. Lowstand carbonates, highstand sandstones? Sediment. Geol. 2003, 155, 1-12. [CrossRef]

18. Pais, J.; Legoinha, P.; Elderfield, H.; Sousa, L.; Estevens, M. The Neogene of Algarve (Portugal). Ciências da Terra (UNL) 2000, 14, 277-288. Available online: http:/ / hdl.handle.net/10362/4720 (accessed on 11 March 2018).

19. Moura, D.; Boski, T. Unidades litostratográficas do Pliocénico e Plistocénico no Algarve. Comunicações do Instituto Geológico e Mineiro 1999, 86, 85-106.

20. Costa, M.; Silva, R.; Vitorino, J. Contribuição para o estudo do clima de agitação maríima na costa portuguesa. In 2as Jornadas Portuguesas Engenharia Costeira e Portuária; International Navigation Association PIANC: Sines, Portugal, 2001; pp. 1-20.

21. Trenhaile, A.S. Modeling the development of wave-cut shore platform. Mar. Geol. 2000, 166, $163-178$. [CrossRef]

22. Trenhaile, A.S. Rock coasts, with particular emphasis on shore platform. Geomorphology 2002, 48, 7-22. [CrossRef]

23. Kogure, T.; Aoki, H.; Hirose, T.; Matsukura, Y. Effect of the development of notches and tension cracks on instability of limestone coastal cliffs in the Ryukyus, Japan. Geomorphology 2006, 80, 236-244. [CrossRef]

24. Moura, D.; Gabriel, S.; Jacob, J. Coastal morphology along the Central Algarve rocky coast: Driver mechanisms. J. Coast. Res. 2011, SI61, 790-794.

25. Paredes, C.; Castedo, R.; Llorente, M.; Lain, L. A predictive evolution model of rocky coasts. Revista Internacional de Métodos Numéricos para Cálculo y Diseño 2012, 28, 243-255. [CrossRef]

26. Castedo, R.; Murphy, W.; Lawrence, J.; Paredes, C. A new process-response coastal recession model of soft rock cliffs. Geomorphology 2012, 177, 128-143. [CrossRef]

27. Wallance, J.; Morris, B.; Howarth, P. Identifying structural trend with fractal dimension and topography. Geology 2006, 34, 901-904. [CrossRef]

28. Ali, T. On the Selection of an Interpolation Method for Creating a Terrain Model (TM) from LIDAR Data. Available online: https:/ / pdfs.semanticscholar.org/44db/ad38a28672e3651ad330092e466d241f8764.pdf (accessed on 10 June 2018).

29. Brodu, N.; Lague, D. 3D terrestrial lidar data classification of complex natural scenes using a multi-scale dimensionality criterion: Applications in geomorphology. ISPRS J. Photogramm. Remote Sens. 2012, 68, 121-134. [CrossRef]

30. Hobbs, P. Coastal Cliff monitoring. Geo-connex. UK 2008, 6, 16-17. Available online: http://nora.nerc.ac.uk/ 3668 (accessed on 10 March 2018).

31. Kogure, T.; Matsukura, Y. Critical notch depths for failure of coastal limestone cliffs: Case study at Kuro-shima Island, Okinawa, Japan. Earth Surf. Process Landf. 2010, 35, 1044-1056. [CrossRef]

32. James, M.R.; Robson, S. Straightforward reconstruction of 3D surfaces and topography with a camera: Accuracy and geoscience application. J. Geophys. Res. Earth Surf. 2012, 117, F03017. [CrossRef]

(C) 2018 by the authors. Licensee MDPI, Basel, Switzerland. This article is an open access article distributed under the terms and conditions of the Creative Commons Attribution (CC BY) license (http://creativecommons.org/licenses/by/4.0/). 